\section{HSE}

Historia Social y de la Educación

Social and Education History
Hipatia Press

www.hipatiapress.com

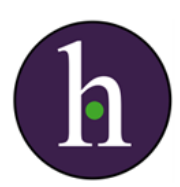

Instructions for authors, subscriptions and further details:

http://hse.hipatiapress.com

\title{
Los gitanos y gitanas de España a mediados del siglo XVIII. EI fracaso de un proyecto de "exterminio" (1748-1765)
}

Maria Jesús Márquez Garcia ${ }^{1}$

1) Universidad de Valladolid (España)

Date of publication: October $23^{\text {rd }}, 2015$

Edition period: Edition period: October 2015-February 2016

To cite this article: Márquez, M. J. (2015). Los gitanos y las gitanas de España a mediados del siglo XVIII. El fracaso del proyecto de "exterminio" (1748-1765) [Review of the book]. Social and Education History 4(3), 312314 doi:10.17583/hse.2015.1737

To link this article: http://dx.doi.org/10.17583/hse.2015.1737

\section{PLEASE SCROLL DOWN FOR ARTICLE}

The terms and conditions of use are related to the Open Journal System and to Creative Commons Attribution License (CC-BY). 
HSE - Social and Education History Vol. 4 No. 3 October 2015 pp.

312-314

\section{Reviews (II)}

Martínez Martínez, Manuel (2014) Los gitanos y las gitanas de España a mediados del siglo XVIII. EL fracaso de un proyecto de "exterminio" (17481765). Almería. Universidad de Almería

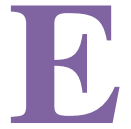

1 autor de esta obra nos introduce en un momento histórico que pone el foco en el proceso de exterminio de los gitanos españoles que propició Fernando VI, organizado por el Marqués de Ensenada y que se extendió desde 1748 a 1765 . Un periodo oscuro de nuestra historia que no puede pasar desapercibido para la humanidad; la memoria detallada de la persecución al colectivo gitano tal y como reconstruye la obra, nos sitúa en un contexto de injusticia, dominio y resistencia que sin duda forma parte de un desalmado periodo de la historia de este país.

El libro está basado en una tesis doctoral rigurosa y con una aportación histórica relevante. El entramado del periodo de mayor exterminio xenófobo se va despejando en una búsqueda extensa y minuciosa de documentos y datos de distintas fuentes documentales; algunas inéditas como el archivo general de Simancas, sección Guerra Moderna y otras ya utilizadas por historiadores, tales como el archivo del departamento Marítimo de Cartagena y el Libro de Actas del Archivo Provincial de Zaragoza, que prestan a este trabajo el necesario rigor científico. Aporta, además, una amplia base documental y una exhaustiva búsqueda bibliográfica para abordar la temática que nos ocupa.

2015 Hipatia Press

ISSN: 2014-3567

DOI: $10.17583 / \mathrm{hse} .2015 .1737$

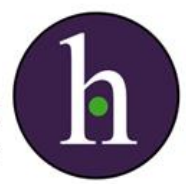




\section{HSE - Social and Education History, 4(2) 313}

La obra reconstruye con evidencias textuales recogidas con detalle la época referenciada, en una narrativa que nos acerca a la trama y tensiones de la Gran Redada que sufre la población gitana introduciendo al lector y lectora en el contexto humano, geográfico y político.

El hilo histórico de este oscuro periodo se desarrolla en cuatro capítulos: el primero aborda cómo se va gestando el proceso de persecución que se desencadena en 1749 y se desarrolla en forma diferente según los territorios durante 16 años. Se inicia este capítulo con una referencia al origen de esta persecución que se consolida en el último cuarto del siglo XVI. Se incluyen una serie de cuadros y tablas en donde se sintetizan aspectos de la minuciosa planificación, instrucciones, preparativos, destinos, y cuantificaciones de las redadas, que se acompaña con ilustraciones alusivas al intento de exterminio de los gitanos.

El segundo capítulo, está dedicado a la narrativa de los destinos de hombres y muchachos gitanos por la geografía de España, y a los oficios a los que se le iba a dedicar, fundamentalmente a servir en la marina en los Arsenales, de Cartagena, La Carraca en Cádiz, La Graña en Ferrol, etc., los navíos y batallones. Con referencias de ciudades, oficios y número de hombres y muchachos deportados. Se detalla la lucha, resistencia y ansia de fuga y las enfermedades y muertes que se produjeron debido al hacinamiento al que se le había confinado.

Sin duda el capítulo tercero es la aportación más novedosa de esta obra por la extensión que dedica el autor a documentar y describir la situación de las mujeres gitanas en este periodo. Aborda las redadas de las mujeres víctimas de la prisión general, apartadas de la sociedad y encerradas en hospicios y casas de misericordia. El único objetivo era tenerlas separadas de los hombres para evitar la reproducción y supervivencia del pueblo gitano. Este tema como indica el autor es tratado en este capítulo de forma extensa y con profundidad.

El cuarto capítulo nos introduce en el final del túnel y el largo y arduo camino hacia la libertad. Las condiciones de miseria, calamidades y 
desesperación que vivieron los hombres y mujeres gitanas en cautiverio se vieron dilatadas hasta algunos años después de 1763. Los indultos fueron esporádicos y detallados, los intentos de liberación se retrasaban, como el iniciado por el Duque de Calyus, su actitud hacia la situación en que se encontraban los gitanos cambió cuando conoció de primera mano las experiencias y penalidades de las gitanas que quedaron bajo su jurisdicción y le hizo apreciar a un pueblo castigado injustamente. Sin embargo, hay que esperar la entronización de Carlos III en 1761en la que de nuevo se manifiesta el deseo de indulto y se va dejando atrás el periodo de exterminio "la desconfianza y la presunción de culpabilidad no acabaron del todo, manteniéndose la prohibición de su lengua y vestimenta, así como el control de sus desplazamientos y vecindades, medidas que se mantuvieron hasta bien entrado el siglo XIX".

María Jesús Márquez García Departamento Pedagogía Facultad Educación Soria Universidad de Valladolid mariajesus.marquez@uva.es 